\title{
[99mTc]MIBI scintigraphy in a patient with thyroid follicular neoplasm: a case report and review of literature
}

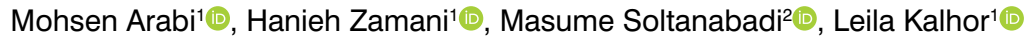 \\ ${ }^{1}$ Department of Nuclear Medicine, Alborz University of Medical Sciences, Karaj, Iran \\ 'Department of Nuclear Medicine, Shahrekord University of Medical Sciences, Shahrekord, Iran
}

[Received 24 II 2021; Accepted 15 III 2021]

\begin{abstract}
[99mTC]MIBI thyroid scintigraphy is a useful tool to differentiate benign from malignant thyroid nodules. This report aims to show the diagnostic performance of [99mTc]MIBI scintigraphy used in an 83-year-old woman who had a thyroidectomy about 7 years ago. She had a mass of thyroid which was very large, non-homogenous and painless. [ ${ }^{99 \mathrm{~m} T C] M I B I}$ scintigraphy could be a pre-surgical method to investigate the follicular nodules and predicting the malignant form of thyroid nodules. Also, it will provide tissue information for ${ }^{[99 \mathrm{~m} T c] M I B I}$ images in thyroid lesions.
\end{abstract}

KEY words: [99mTc]MIBI scintigraphy; patient; thyroid follicular neoplasm

Nucl Med Rev 2021; 24, 2: 118-119

\section{Introduction}

The prevalence of thyroid nodules is about $5 \%$ even in areas with adequate iodine intake [1]. The risk of thyroid nodules is about $3-5 \%$ [2]. Thyroid cancer has been one of the most diagnosed forms of cancers around the world in the past few decades [3]. The $2^{\text {nd }}$ most common thyroid cancer is follicular thyroid cancer, and it is a higher incidence of distant metastases. Therefore, the prognosis is worse than the more common papillary thyroid carcinoma [4-6]. Thyroid gland follicular neoplasm comprises follicular carcinoma and adenoma.

\section{Case presentation}

An 83-year-old woman came for a nuclear thyroid scan. After examination of her neck, the mass of thyroid was non-homogenous, enlarged, difficult to be examined and firm and painless. She had a thyroidectomy 7 years ago but did not know the details of whether it was a total or hemithyroidectomy. After 4 years of recurrence, the physician advised her to have another surgery, but the patient was not satisfied. After scanning of the patient's thyroid with [99mTc] pertechnetate, it was observed that this mass had no uptake,

Correspondence to: Leila Kalhor

Department of Nuclear Medicine, Alborz University of Medical Sciences

Karaj, Iran

e-mail: kalhorleila169@gmail.com

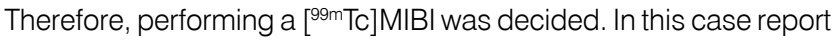

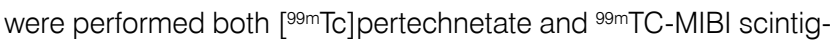
raphy in anterior projection. The study showed poor delineation of the thyroid gland in [ $\left.{ }^{99 \mathrm{~m} T c}\right]$ pertechnetate thyroid scan (Fig. 1). In the $\left[{ }^{99 m} \mathrm{Tc}\right] \mathrm{MIBI}$ scan, an area of increased uptake is noticed on the left lobe of the thyroid corresponding to a palpable nodule. The left lobe of the thyroid was enlarged with a rather in-homogenous radiotracer uptake. There was no significant radiotracer activity in the right lobe of the thyroid (due to previous surgery) (Fig. 2). With the patient's history (previous thyroidectomy), scan findings (MIBI avid lesions of the left lobe) showed highly tumour recurrence and after following up she was diagnosed with follicular carcinoma.

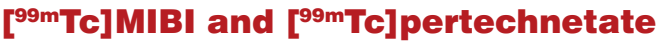 scintigraphy}

Twenty minutes after IV injection of $111 \mathrm{MBQ}$ (3 MCI) [99mTC] pertechnetate and twenty minutes after IV injection of $148 \mathrm{MBQ}$ $(4 \mathrm{MCl})\left[{ }^{99 \mathrm{~m} T c}\right] \mathrm{MIBI}$, thyroid imaging was performed in anterior projection.

\section{Discussion}

[99mTc]MIBI scans have been used to study myocardial perfusion since 1989, but the uptake of this radiopharmaceutical into tumours has led to its use in the study of breast, bone, thyroid, parathyroid, and brain tumours [7]. Numerous studies examining 


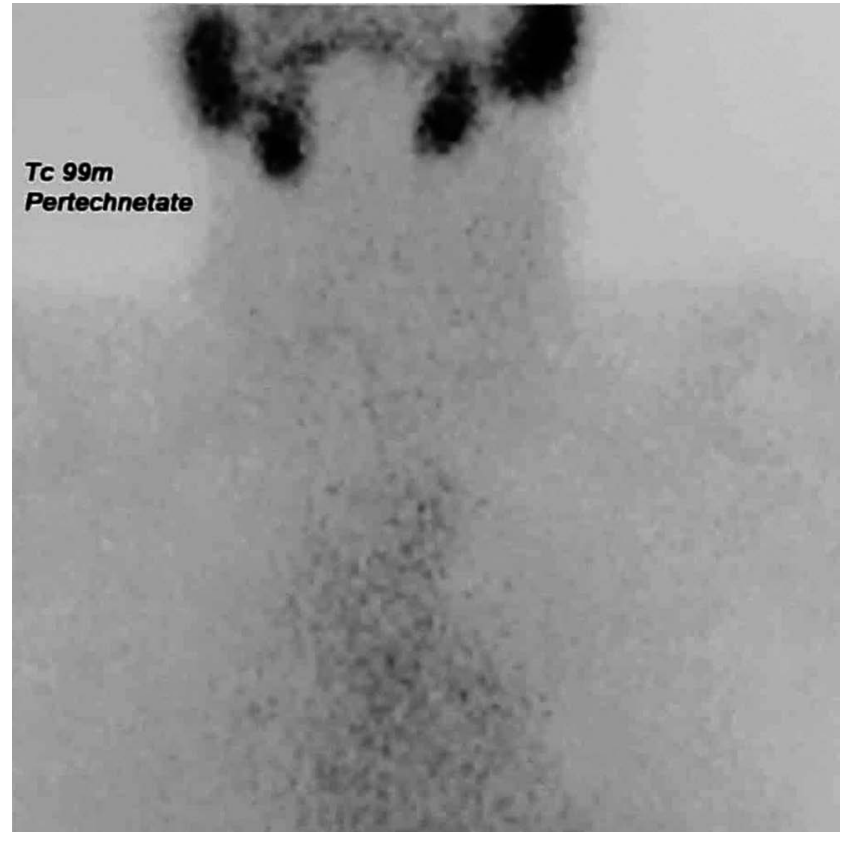

Figure 1. Non-visualized of thyroid gland with thyroid scan and [99mTc] pernectetat

thyroid scans with $\left.{ }^{99 m} \mathrm{TC}\right] \mathrm{MIBI}$ show conflicting results [8]. In a study of 34 operated thyroid nodules, it was concluded that the rate of absorption of $\left.{ }^{99 \mathrm{~m}} \mathrm{Tc}\right] \mathrm{MIBI}$ in the thyroid nodule is mainly a sign of thyroid tissue viability and is not specific to malignancy [9]. But another study [7] on thyroid nodules found that high uptake of $\left.{ }^{99 \mathrm{~m}} \mathrm{Tc}\right] \mathrm{MIBI}$ significantly increased the risk of malignancy. The researchers suggested routine use of $\left.{ }^{99 \mathrm{~m}} \mathrm{Tc}\right] \mathrm{MIBI}$ scan with fine-needle aspiration in the diagnosis of cold thyroid.

Nowadays, fewer than $25 \%$ of nodules (follicular neoplasm) show malignant features at histological examination [10, 11]. Some studies expressed that $\left[{ }^{99 \mathrm{~m} T c]} \mathrm{MIBI}\right.$ scintigraphy is a reliable procedure to improve the accuracy of diagnostic thyroid fine-needle aspiration cytology (FNAC) $[2,1213]$. Several authors observed that [99mTC]MIBI scintigraphy is positive in both malignant and benign thyroid lesions $[13,14]$ and $\left[{ }^{99 m} \mathrm{TC}\right] \mathrm{MIBI}$ thyroid scintigraphy is highly accurate in the differential diagnosis of nodules with indeterminate cytology finding [15].

We can conclude that $\left.{ }^{99 \mathrm{~m}} \mathrm{Tc}\right] \mathrm{MIBI}$ scintigraphy could be a pre-surgical method to investigate follicular nodules and predicting the malignant thyroid nodules. Therefore, the scintigraphy of $\left[{ }^{99 m} \mathrm{Tc}\right] \mathrm{MIBI}$ provides tissue information for these scintigraphy images in thyroid nodules.

\section{Conflict of interest}

The authors declare that they do not have any conflict of interest.

\section{References}

1. Schlumberger MJ, Feletti S, Hay I. Nontoxic goiter and thyroid neoplasm In: Williams text book of endocrinology. 10th edition. Philadelphia: Saunders. 2003: 465.

2. Hegedüs L, Bonnema SJ, Bennedbaek FN. Management of simple nodular goiter: current status and future perspectives. Endocr Rev. 2003; 24(1): 102-132, doi: 10.1210/er.2002-0016, indexed in Pubmed: 12588812.

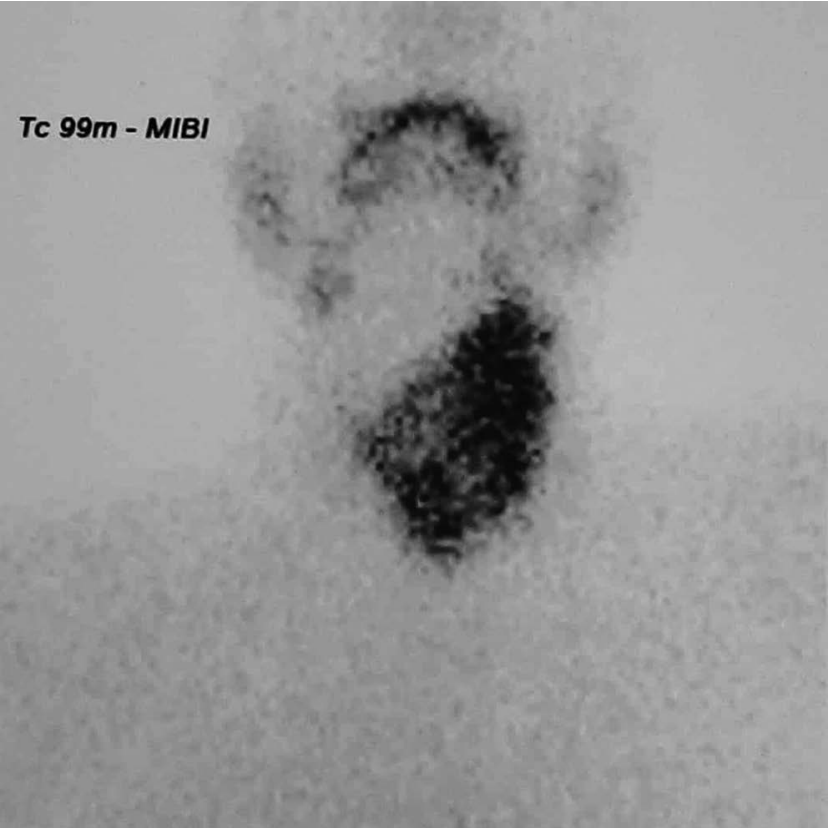

Figure 2. Left lobe of the thyroid

3. Howlader N, et al. SEER Cancer Statistics Review, Populations, National Cancer Institute. 1975

4. Podda M, Saba A, Porru F, et al. Follicular thyroid carcinoma: differences in clinical relevance between minimally invasive and widely invasive tumors. World J Surg Oncol. 2015; 13: 193, doi: 10.1186/s12957-015-0612-8, indexed in Pubmed: 26041024.

5. Brennan M, Bergstralh E, van Heerden J, et al. Follicular Thyroid Cancer Treated at the Mayo Clinic, 1946 Through 1970: Initial Manifestations, Pathologic Findings, Therapy, and Outcome. Mayo Clinic Proceedings. 1991; 66(1): 11-22, doi: 10.1016/s0025-6196(12)61170-7.

6. Hundahl SA, Fleming ID, Fremgen AM, et al. A National Cancer Data Base report on 53,856 cases of thyroid carcinoma treated in the U.S., 1985-1995 Cancer. 1998; 83(12): 2638-2648, doi: 10.1002/(sici)1097-0142(199812 15)83:12<2638::aid-cncr31>3.0.co;2-1, indexed in Pubmed: 9874472.

7. Mezosi E, Bajnok L, Gyory F, et al. The role of technetium-99m methoxyisobutylisonitrile scintigraphy in the differential diagnosis of cold thyroid nodules. European Journal of Nuclear Medicine and Molecular Imaging. 1999; 26(8): 798-803, doi: 10.1007/s002590050451.

8. Kim N, Lavertu P. Evaluation of a thyroid nodule. Otolaryngologic Clinics of North America. 2003; 36(1): 17-33, doi: 10.1016/s0030-6665(02)00130-5.

9. Alonso O, Lago G, Mut F, et al. Thyroid imaging with Tc-99m MIBI in patients with solitary cold single nodules on pertechnetate imaging. Clin Nucl Med. 1996; 21(5): 363-367, doi: 10.1097/00003072-199605000-00002, indexed in Pubmed: 8732828

10. Schlumberger M, Pacini F. Thyroid Tumors. 2nd ed. Paris, France: Editions Nucl' eon. 2003: 18-24.

11. Erdil TY, Ozker K, Kabasakal L, et al. Correlation of technetium-99m MIBI and thallium-201 retention in solitary cold thyroid nodules with postoperative histopathology. Eur J Nucl Med. 2000; 27(6): 713-720, doi: 10.1007/s002590050567, indexed in Pubmed: 10901459

12. Chamnanrabiabkij E, Welch A, Jayapaul MK, et al. Detection of Hurthle cell carcinoma using sestamibi. Thyroid. 2008; 18(5): 575-576, doi: 10.1089/thy.2007.0200, indexed in Pubmed: 18044993

13. Campennì $A$, Siracusa $M$, Ruggeri RM, et al. Differentiating malignant from benign thyroid nodules with indeterminate cytology by Tc-MIBI scan: a new quantitative method for improving diagnostic accuracy. Sci Rep. 2017; 7(1): 6147, doi: 10.1038/s41598-017-06603-3, indexed in Pubmed: 28733644. 